\title{
IMPACTO DA PERCEPÇÃO DE SUPORTE ORGANIZACIONAL SOBRE O COMPROMETIMENTO ORGANIZACIONAL AFETIVO: O PAPEL MODERADOR DA LIDERANÇA
}

\author{
PERCEIVED ORGANIZATIONAL SUPPORT AND ITS INFLUENCE OVER AFFECTIVE \\ ORGANIZATIONAL COMMITMENT: THE ROLE OF LEADERSHIP
}

Recebido em 23.01.2014. Aprovado em 07.10.2014 Avaliado pelo sistema double blind review

DOI: http://dx.doi.org/10.12712/rpca.v8i4.396

\section{Cintia Monteiro Fernandes}

cintia.fernandes@metodista.br

Universidade Metodista de São Paulo - São Bernardo do Campo - SP - Brasil

\section{Mirlene Maria Matias Siqueira}

mirlenesiqueira@uol.com.br

Universidade de Coimbra - Coimbra - Portugal

\section{Almir Martins Vieira}

almir.vieira@gmail.com

Universidade Metodista de São Paulo - São Bernardo do Campo - SP - Brasil

\section{Resumo}

Este trabalho tem como objetivo analisar as relações entre estilos de liderança, percepção de suporte organizacional e comprometimento organizacional afetivo em trabalhadores. Participaram da pesquisa 263 trabalhadores que atuam na Região Sudeste do Brasil (Rio de Janeiro e São Paulo) em organizações não governamentais, públicas e privadas. Como instrumento para coleta de dados, foi utilizado um questionário de autopreenchimento composto de três escalas que mediram as variáveis da pesquisa. 0 estudo se propôs a apresentar, interpretar e discutir as relações entre as variáveis, como também, testar as hipóteses referentes ao modelo conceitual proposto, por meio de uma pesquisa de natureza transversal com abordagem quantitativa, cujos dados coletados foram analisados por aplicação de técnicas estatísticas. 0 tratamento e análise dos dados foram realizados pelo software estatístico Statistical Package for the Social Sciences - SPSS. Os resultados obtidos demonstraram que a variável "percepção de suporte organizacional" exerce forte e significativo impacto sobre comprometimento organizacional afetivo, enquanto que a variável "estilos de liderança" não consegue aumentar nem diminuir a força. A pesquisa possibilitou concluir que a variável "estilos de liderança" é um moderador frágil da relação entre percepção de suporte organizacional e comprometimento organizacional afetivo.

Palavras-chave: Estilos de liderança. Percepção de suporte organizacional. Comprometimento organizacional afetivo. 


\section{Abstract}

The general aim of this paper was to analyze the relation among leadership styles, perception of organizational support and affective organizational commitment of workers. There were 263 workers who attended the survey in Southeast Brazil (Rio de Janeiro and Sao Paulo) in public, private and non-governmental organizations. As an instrument for data collection, it was used a self-fulfillment questionnaire composed of three scales that were able to measure the research variables. This study proposes to understand and to discuss the relation among variables as well as to test the hypotheses concerning the proposed conceptual model through a cross-cutting research with a quantitative approach which data were analyzed by applying parametric statistic techniques. Treatment and analysis were performed by the statistical software Statistical Package for Social Sciences - SPSS. The results obtained showed that the variable of perception of organizational support has a strong and significant impact on affective organizational commitment while the variable of leadership styles is not substantial enough. The research indicated that the variable of leadership styles is a fragile moderator of the relation between perception of organizational support and affective organizational commitment.

Keywords: Leadership. Perceived organizational support. Affective organizational commitment.

\section{Introdução}

Ao longo das últimas décadas, as organizações têm passado por várias alterações, desde a sua estrutura produtiva até o comportamento dos indivíduos no ambiente de trabalho. 0 desenvolvimento global e o amplo acesso às novas tecnologias exigem cada vez mais das organizações novos padrões de comportamento para que se mantenham competitivas.

A fim de passar por grandes desafios com êxito, os gestores/líderes têm buscado formas de compreender a relação entre organização e seus empregados, com a finalidade de liderá-los com sucesso e não só atender as necessidades do subordinado, bem como da organização.

Partindo desta premissa, são apresentadas neste estudo diversas proposições teóricas acerca de estilos de liderança defendidos por pensadores no século XX, como Hersey e Blanchard (1986). Posteriormente, abordar-se-á o tema da percepção de suporte organizacional, que é um construto definido por Eisenberger, Huntington, Hutchison e Sowa (1986), enquanto crença global sobre o quanto a organização preocupa-se com o bem-estar e valoriza as contribuições de seus empregados. Finalmente, o estudo traz o tema comprometimento organizacional afetivo, que segundo Mowday, Steers e Porter (1979, p. 225), é um estado em que o empregado se identifica com a organização, assim como seus objetivos, e nela deseja manter-se a fim de facilitar tais objetivos.

Diante deste cenário, este trabalho tem como objetivo analisar as relações entre estilos de liderança, percepção de suporte organizacional e comprometimento organizacional afetivo em trabalhadores da Região Sudeste do Brasil, cuja postura metodológica assumiu uma abordagem quantitativa, instrumentalizada por questionário elaborado a partir de três escalas: avaliação do estilo gerencial, percepção de suporte organizacional e comprometimento organizacional afetivo. Para tanto, este artigo foi organizado em quatro partes, além desta introdução. A primeira contém um levantamento da literatura pertinente ao assunto, a partir da qual são apresentadas as concepções teóricas e os estudos que focalizaram os estilos de liderança, a percepção de suporte organizacional e o comprometimento organizacional afetivo. A parte seguinte apresenta o método adotado para o alcance dos objetivos do estudo, na qual se assume a abordagem metodológica, bem como se apresenta o instrumento utilizado para coleta dos dados. Na terceira parte são apresentados, interpretados e discutidos os resultados das análises 


\section{Cintia Monteiro Fernandes, Mirlene Maria Matias Siqueira e \\ Almir Martins Vieira}

descritivas referentes às médias e desvios-padrão, índices de precisão, valores do teste $t$ e correlações ( $r$ de Pearson) das variáveis estilos de liderança, percepções de suporte organizacional e comprometimento organizacional afetivo.

Por fim, na quarta parte, são apresentadas as considerações finais sobre o desafio empírico assumido, além de recomendações para estudos futuros.

\section{Liderança}

O tema liderança é tratado por diversos autores (LEWIN; LIPPITT; WHITE, 1939; HERSEY; BLANCHARD, 1986; LIKERT; 1971; BLAKE; MOUTON 1975), tendo despertado, desde o século passado, interesse entre gestores organizacionais e pesquisadores na área do comportamento organizacional. Em geral, as definições de liderança encontradas no campo acadêmico seguem a lógica de conservar o denominador comum de que o ato de liderar vincula-se necessariamente a um fenômeno grupal, isto é, envolve duas ou mais pessoas. Tal como afirma Bergamini (1994), trata-se de um processo de influência sobre o (s) outro (s), exercido de forma intencional por parte do (s) líder (es) sobre seu (s) seguidor (es). Seguindo o mesmo ponto de vista, Robbins (1999) menciona a capacidade que o líder tem de influenciar um grupo em direção à realização de metas.

\section{Estilos de Liderança}

O psicólogo alemão Kurt Lewin é considerado pioneiro no campo da Teoria Comportamental (PANTOJA, 2005), pois foi um dos principais impulsionadores no estudo da motivação como fator influenciador no desempenho dos empregados. Lewin, Lippitt e White (1939) conduziram pesquisas no estado de Iowa (Estados Unidos) no final da década de 1930, identificando três estilos de liderança: autocrático, de postura centralizadora; democrático (ou participativo), que estimula a participação; e laissez-faire, de caráter descentralizador (quadro 1).

\begin{tabular}{|c|c|c|}
\hline $\begin{array}{ll}\text { Estilo } & \text { de } \\
\text { Liderança } & \end{array}$ & Características & \\
\hline Autocrático & $\begin{array}{l}\text { Deseja, principalmente, a obediência do grupo. É ele que determina a política administrativa e } \\
\text { considera que a responsabilidade da decisão deve afetar a uma pessoa somente. } 0 \text { gestor é o } \\
\text { que inicia suas ideias, seus planos, que são executados. É o tipo centralizador; }\end{array}$ & 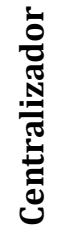 \\
\hline $\begin{array}{l}\text { Democrático ou } \\
\text { participativo }\end{array}$ & $\begin{array}{l}\text { Procura ouvir as ideias e sugestões do grupo consultando-o e conversando com os } \\
\text { subordinados. Os componentes do grupo são encorajados no sentido de estabelecer a política } \\
\text { administrativa. A atribuição do gestor é mais a de um moderador de opiniões. Este estilo de } \\
\text { liderança enseja a cooperação de seu grupo. O grupo é o elemento central, visto que as } \\
\text { habilidades, as ideias e a energia de todo o grupo forma o reservatório onde o líder consegue o } \\
\text { "material" para as realizações. }\end{array}$ & 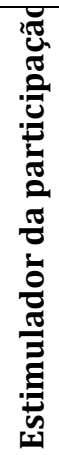 \\
\hline
\end{tabular}

Quadro 1: Estilos de liderança proposto por Lewin, Lippett e White em Iowa nos EUA no final da década de 1930 Fonte: Adaptado de Uris (1967) 


\section{IMPACTO DA PERCEPÇÃO DE SUPORTE ORGANIZACIONAL SOBRE O COMPROMETIMENTO ORGANIZACIONAL AFETIVO: O PAPEL MODERADOR DA LIDERANÇA}

As diferenças entre os estilos de liderança apresentados situam-se no nível da participação dos empregados nas decisões. Estes estilos forneceram uma chave essencial para estudos posteriores sobre liderança (PANTOJA, 2005). De acordo com Uris (1967), há uma relação entre os estilos de liderança e as atividades dos empregados: no estilo democrata, os funcionários tendem a cooperar, no autocrata, tendem a obedecer, e no liberal, a serem eficientes.

Ao final da década de 1940, após a Segunda Guerra Mundial, destacaram-se os estudos da Ohio State University, por meio dos quais o objetivo era identificar dimensões independentes do comportamento do líder (LIKERT, 1971). Dentre os principais achados, foram identificadas duas dimensões no comportamento dos líderes: (1) estrutura inicial: capacidade para definir e estruturar o seu papel como líder e dos empregados na busca para a realização de metas e (2) consideração: capacidade para estabelecer relações de trabalho baseadas em confiança mútua, respeito pelas ideias dos empregados e interesse por seus sentimentos.

Para Aronson (2001), pesquisas baseadas nas duas dimensões propostas pelos estudiosos da Ohio State University revelaram que os líderes com alto grau de estrutura inicial e de consideração, obtêm altos índices de desempenho e satisfação dos empregados com maior frequência do que aqueles com baixa pontuação em uma das duas dimensões ou em ambas, chegando à conclusão de que o estilo "alto-alto" (alto em estrutura inicial e alto na dimensão consideração) traz resultados positivos. A escala para avaliar as duas dimensões é a LBDQ (Leader Behavior Description Questionnaire) utilizada para medir o "líder ideal" (ARONSON, 2001). Na mesma época dos estudos dessa universidade, o Institute for Social Research deu início, em 1947, a um programa de pesquisas em grande escala, empregando novas metodologias para estudar os complexos problemas humanos da administração. 0 objetivo era muito similar aos estudos da Ohio State University: identificar as características de comportamento do líder relacionadas à sua eficácia.

Blake e Mouton (1975) desenvolveram uma representação bidimensional dos estilos de liderança, seguindo dessa forma, a tendência comportamental. A primeira publicação ocorreu em 1964, com o livro "The Managerial Grid”. Os autores propuseram cinco estilos de liderança combinados em duas dimensões: preocupação com a produção e preocupação com os empregados. A preocupação com a produção inclui resultados, base, desempenho, lucro ou missão. A produção é tudo aquilo para cuja realização uma organização emprega pessoas, podendo ser representada por um líder na organização através de novas ideias, que as converterá em itens vendáveis, ou por um trabalho físico. A preocupação com a produção poderá tomar a forma de mensurações de eficiência, número de unidades produzidas versus tempo de trabalho, versus qualidade (BLAKE; MOUTON, 1975). A preocupação com os empregados revela-se de múltiplas e variadas formas. As preocupações de alguns líderes tornam-se visíveis em seus esforços por assegurar estima dos empregados. Outros tipos de líderes preocupam-se com a execução do trabalho pelos empregados (BLAKE; MOUTON, 1975).

De acordo com Melo (2001), a evolução dos estudos mostrou com clareza que prever o sucesso do estilo de liderança era mais complexo do que isolar traços ou determinados comportamentos preferidos. 0 estilo de liderança ideal buscado até então, procurava mostrar ao líder a relevância de determinados conceitos vistos neste estudo.

Nesse contexto, surge a expressão inteligência emocional, que do ponto de vista teórico e empírico, foi utilizada pela primeira vez por Mayer, DiPaolo e Salovey (1990), tornando-se conhecida na década de 1990 pela obra de Goleman (1995), intitulada "Inteligência Emocional", que a apresentou posteriormente sob a perspectiva dos estilos de liderança (GOLEMAN, 2002).

Os resultados apontaram que a inteligência emocional estaria relacionada ao monitoramento dos sentimentos em si e nos outros, na discriminação entre ambos e na utilização desta 
informação para guiar o pensamento e as ações. No quadro 2 são descritos os estilos de liderança que surgiram de diferentes componentes da inteligência emocional propostos pelo autor.

\begin{tabular}{|c|c|c|}
\hline $\begin{array}{l}\text { Estilo de } \\
\text { liderança }\end{array}$ & Descriç̧ão & \\
\hline Coercitivo & $\begin{array}{l}\text { É menos eficaz em muitas situações. Levando-se em consideração o que o } \\
\text { estilo faz ao clima da organização, é na flexibilidade que acontece o mais duro } \\
\text { golpe. A decisão extrema do líder, de cima para baixo, destrói o nascimento de } \\
\text { novas ideias. Os subordinados sentem-se desrespeitados, da mesma forma, o } \\
\text { senso de responsabilidade dela evapora: incapazes de agir por sua própria } \\
\text { iniciativa, perdem seu senso de posse e se sentem-se pouco responsabilizados } \\
\text { por seus desempenhos. }\end{array}$ & 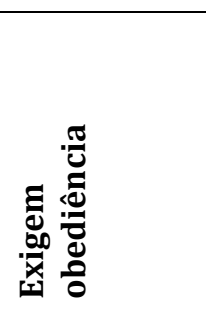 \\
\hline $\begin{array}{l}\text { Confiável } \\
\text { ou } \\
\text { Visionário }\end{array}$ & $\begin{array}{l}\text { Este estilo, de acordo com os resultados da pesquisa, indica que é mais o } \\
\text { confiável e eficaz, conduzindo para cima todos os aspectos do clima que } \\
\text { adquiri clareza. O líder confiável é um visionário, ele motiva as pessoas por } \\
\text { meio de esclarecimentos de como seus trabalhos se encaixam dentro de uma } \\
\text { grande visão para a organização. Os empregados que trabalham para tais } \\
\text { líderes entendem que o que eles fazem importa e por que importa. Essa } \\
\text { liderança também maximiza o compromisso com os objetivos e com a } \\
\text { estratégia da organização. Dessa forma, ao enquadrar a tarefa individual } \\
\text { dentro de uma grande visão, o líder confiável define padrões que giram em } \\
\text { torno dessa visão. Os padrões para o sucesso são claros para todos, assim } \\
\text { como as recompensas. }\end{array}$ & 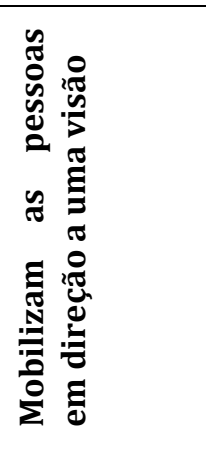 \\
\hline Agregador & $\begin{array}{l}\text { O estilo agregador gira em torno das pessoas - propõe valores individuais e } \\
\text { emocionais mais do que tarefas e objetivos. O líder agregador aspira por } \\
\text { manter os funcionários felizes e criar harmonia entre eles. Controla por meio } \\
\text { da construção de fortes laços emocionais e, então, colhe os benefícios dessa } \\
\text { abordagem denominada intensa lealdade. Tem efeito positivo na } \\
\text { comunicação. Os líderes confiáveis estabelecem uma visão, determinam } \\
\text { padrões e deixam que os empregados saibam como seus trabalhos estão } \\
\text { promovendo os objetivos do grupo. Alternando-se com cuidado e cultivando a } \\
\text { abordagem do líder agregador, tem-se uma combinação eficiente. }\end{array}$ & 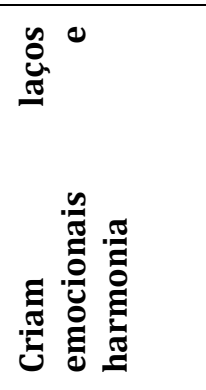 \\
\hline Democrático & $\begin{array}{l}\text { O líder democrático abastece-se por desprender seu tempo obtendo ideias } \\
\text { dos empregados, construindo confiança, respeito e compromisso. Ao deixar } \\
\text { os membros de sua equipe participar das decisões que afetam seus objetivos } \\
\text { e como fazer esse trabalho, o líder democrático conduz à elevação da } \\
\text { flexibilidade e da responsabilidade. Por poderem opinar no estabelecimento } \\
\text { de seus objetivos e nos padrões para avaliar o sucesso, as pessoas que } \\
\text { operam em um sistema democrático tendem a ser muito realistas a respeito } \\
\text { do que pode e do que não pode se executado. }\end{array}$ & 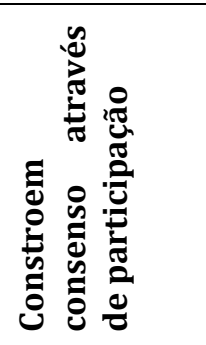 \\
\hline Agressivo & $\begin{array}{l}\text { Estabelece padrões de desempenho extremamente altos, é obsessivo a } \\
\text { respeito de como fazer as coisas melhor e mais rápidas, e pede o mesmo de } \\
\text { todos à sua volta. Aponta com exatidão os desempenhos medíocres e exige } \\
\text { mais dos subordinados. Se, por acaso, eles não se elevam com a oportunidade, } \\
\text { o líder os substitui por pessoas que possam fazer a tarefa. }\end{array}$ & 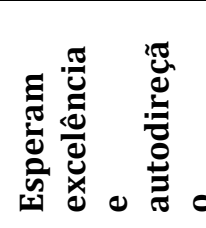 \\
\hline Conselheiro & $\begin{array}{l}\text { O líder conselheiro ajuda os funcionários a identificar suas forças e fraquezas } \\
\text { exclusivas e atá-las às suas aspirações pessoais e de carreira. Encoraja os } \\
\text { subordinados a estabelecer em um desenvolvimento de objetivos de longo } \\
\text { prazo e os ajuda a idealizar um plano para alcançá-los. O líder faz acordos } \\
\text { com seus funcionários a respeito de seus papéis e responsabilidades em } \\
\text { desempenhar planos em desenvolvimento e dá suficiente instrução e } \\
\text { feedback. }\end{array}$ & 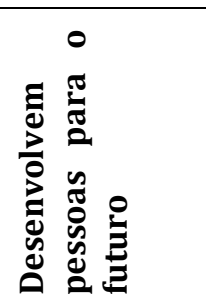 \\
\hline
\end{tabular}

Quadro 2. Estilos de liderança em função da inteligência emocional 
Fonte: adaptado de Goleman (2002)

O estilo de liderança é um tema que desperta interesse entre pesquisadores no cenário nacional e internacional. Somech (2006) buscou estudar os estilos de liderança participativa e autocrática. Os dados foram coletados a partir de 5 equipes sendo compostas por 290 médicos, 692 enfermeiros, 100 assistentes sociais, 138 terapeutas ocupacionais e 72 nutricionistas. Os resultados apontaram que as equipes heterogêneas apresentaram um estilo de liderança participativa associado por sua vez com a reflexão e inovação das equipes.

O estudo de Euwema, Wendt e Emmerik (2007) investigou os efeitos da cultura da sociedade e o papel moderador da cultura sobre a relação entre a direção e liderança de apoio. Os dados foram coletados junto a 20.336 gestores e 95.893 membros. Estes participantes estavam formados em equipes localizadas em 33 países. De acordo com os autores, na análise foram utilizadas duas dimensões de Hofstede (2001): Individualismo (IDV) e distância do poder (PD). Não houve relação direta entre essas dimensões culturais e comportamento de cidadania organizacional. 0 estilo de liderança autocrática teve um impacto negativo em relação ao estilo de liderança participativa.

Johnson e Klee (2007) realizaram um estudo fenomenológico, exploratório e qualitativo, no qual seu objetivo era diagnosticar o comportamento do líder nos diferentes estilos de liderança (autocrático, transacional, e transformacional). Os autores tentaram apontar, por meio dessa pesquisa, os estilos de liderança que promovem o comportamento "passivo-agressivo" no local de trabalho. Foram feitas entrevistas individuais com moradores da cidade de Filadélfia (EUA). Sem exceção, todos expressaram a experiência com estilos de liderança autocrático, transacional, e transformacional. Dois deles indicaram que a liderança autocrática era a mais predominante; cinco viram a liderança transacional como a mais predominante em locais de trabalho; um disse que uma combinação de estilos era predominante; e um outro participante não soube informar; dois relataram que todos os estilos eram predominantes nas organizações. Os autores concluíram que a liderança autocrática incentiva mais o comportamento "passivoagressivo" do que os estilos de liderança transacional ou transformacional. Igualmente sustentaram que os líderes coercitivos e inflexíveis que não escutam os empregados, promovem comportamentos passivo-agressivos no local de trabalho.

Davison, Jibao e Huang (2008) testaram um modelo teórico que explicasse o impacto no estilo de liderança na China baseado na confiança (compartilhar seu conhecimento com seus pares). A população do estudo foi compreendida por 239 estudantes do MBA (Master in Business Administration) de uma universidade chinesa. Todos os respondentes eram empregados em tempo integral, trabalhavam em uma variedade de organizações, embora apresentassem características culturais originais. Foi utilizado o questionário da descrição do comportamento LBDQ (Leader Behavior Description Questionnaire) baseado nas duas dimensões propostas pela Ohio State University. Todas as hipóteses comprovaram que a estrutura e a consideração tiveram um efeito significativo em empregados na intenção de compartilhar o conhecimento. Também foram medidas as práticas dos empregados: comportamento da cidadania, frequência da interação e desempenho de confiança do papel do colega. Os autores adaptaram as perguntas para o questionário a partir das concepções de McAllister (1995). Os resultados demonstraram que os líderes chineses são altamente atenciosos e ao mesmo tempo percebem que têm alguma responsabilidade em dar exemplo a seus empregados.

Souza e Tomei (2008) buscaram analisar uma mudança transformacional intencional (mudança que visava alterar a organização como um todo) na qual o diretor demonstrava aspectos de liderança transacional (aquela que enfatiza o trabalho padronizado e tarefas orientadas). A 


\section{Cintia Monteiro Fernandes, Mirlene Maria Matias Siqueira e \\ Almir Martins Vieira}

avaliação do processo de mudança indicou que seus objetivos principais não foram atingidos no período estudado e, portanto, a pesquisa buscou avaliar a parcela de responsabilidade do estilo de liderança nesse insucesso.

Os resultados demonstraram a compatibilidade com os estudos teóricos, indicando que realmente a liderança transacional foi responsável por vários aspectos negativos identificados no período. As autoras chamam a atenção quanto à importância do estilo de liderança exercido em fases de mudança organizacional. Os principais problemas encontrados foram: ausência de visão e de envolvimento dos gestores, que não tinham noção dos objetivos do negócio e se preocupavam apenas com as questões do dia a dia (ações para "apagar incêndio"). Como previsto na teoria sobre mudança transacional, esses problemas foram, em grande parte, ocasionados pelo perfil do diretor - extremamente centralizador, com forte cobrança por resultados, frequentes feedbacks negativos e pouca atenção para as dificuldades e os questionamentos dos empregados. Os estudos concluem que esse estilo de liderança estimula a manutenção do status quo, e não a mudança nem o crescimento da empresa.

Lindgreen, Palmer e Wetzels (2009) tiveram como finalidade discutir a relação entre prática de marketing e estilos de liderança. Foi realizada uma pesquisa exploratória no Reino Unido. Segundo os autores, o uso de moderadores dentro do modelo adotado teria sido mais indicado. Foram utilizados dois instrumentos, um do grupo de pesquisa de Marketing Contemporâneo, e o outro do Multifactorial Leadership Questionnaire (MLQ). Os resultados mostraram que um estilo de liderança transformacional é positivamente associado com a interação e marketing de rede. Gosendo e Torres (2010) buscaram identificar a hierarquia dos valores organizacionais e os estilos de gerenciamento e investigar a influência dos valores organizacionais nos estilos de gerenciamento. A amostra foi composta por 30 empregados com baixa escolaridade. Para o levantamento da percepção dos valores organizacionais predominantes nas empresas, os autores aplicaram o Inventário de Perfis de Valores Organizacionais (IPVO), de Oliveira e Tamayo (2004) e, para a percepção do estilo de gerenciamento praticado nas empresas, foi utilizada a Escala de Avaliação do Estilo Gerencial (EAEG) proposta por Melo (2004). Os resultados apontaram o valor organizacional domínio e o estilo de gerenciamento em tarefa como os mais percebidos pelos empregados. Os valores autonomia e bem-estar aparecem como os melhores preditores para o estilo de liderança baseada no relacionamento. 0 valor conformidade é o único preditor do estilo de liderança baseada em tarefa e o valor autonomia é o melhor preditor do estilo de liderança situacional. Estudo semelhante foi realizado por Siqueira e Vieira (2012), em relação à percepção de valores reais e valores considerados ideiais.

Giri e Santra (2010) buscaram avaliar o impacto da idade, o estágio da carreira e a hierarquia dos empregados nos estilos de liderança. Os dados foram coletados de 324 empregados de diversas organizações na Índia. As organizações pertenciam aos seguintes segmentos: indústria de aço, linhas aéreas, bens imobiliários, telecomunicações, e empresas de tecnologia da informação (TI). Foi usado o Multifactorial Leadership Questionnaire (MLQ) para medir o estilo de liderança. Os resultados revelaram que o estilo de liderança difere significativamente na experiência de trabalho, no estágio da carreira e na hierarquia. Demonstraram também que os empregados com menos experiência têm contagens médias da elevação em estilo de liderança transformacional, em que os líderes transformacionais motivam seguidores para fazer mais do que é esperado deles. Os empregados altamente experientes preferem o estilo de liderança no qual a autoridade do líder não é utilizada. 0 impacto da idade e experiência dos empregados sobre os estilos de liderança encontrados foram positivos e significativos. Isto indica que os empregados com mais experiência no mercado de trabalho têm percepção diferente dos empregados mais novos, pois as expectativas dos empregados mudam com a experiência e esta pode ser a razão que os faz perceber a liderança diferentemente. Outro aspecto observado no 


\section{IMPACTO DA PERCEPÇÃO DE SUPORTE ORGANIZACIONAL SOBRE O COMPROMETIMENTO ORGANIZACIONAL AFETIVO: O PAPEL MODERADOR DA LIDERANÇA}

estudo diz respeito à carga de trabalho, que também varia em estágios diferentes da carreira, o que pode também levar à percepção diferente dos estilos de liderança.

\section{Percepção de Suporte Organizacional}

A Percepção de Suporte Organizacional (PSO) está diretamente relacionada às crenças e expectativas do indivíduo acerca da retribuição e do reconhecimento dado pela organização na qual se insere enquanto participante. De acordo com o trabalho de Eisenberger et al. (1986), o construto PSO compõe-se pelas crenças globais sobre o quanto a organização se preocupa com o bem-estar e valoriza as contribuições de seus empregados. Os estudos relatados anteriormente apontam que o suporte da supervisão é um antecedente de PSO. Desta forma, é possível afirmar que o suporte organizacional percebido pelos funcionários também deve ser observado e analisado no contexto organizacional.

Conforme os autores, as organizações costumam valorizar empregados que demonstram comprometimento, envolvimento, dedicação e lealdade com a organização e com o trabalho. Já os empregados, buscam organizações para trabalhar que lhes proporcionem um bom ambiente. Rhoades e Eisenberger (2002) revisaram mais de 70 estudos sobre a crença dos empregados de quanto a organização preocupa-se com o bem-estar e valoriza as contribuições de seus trabalhadores. Uma meta-análise indicou que as principais categorias de percepção de suporte organizacional para com os trabalhadores são: justiça, suporte do líder e/ou organização, recompensas organizacionais e condições de trabalho favoráveis. A percepção de suporte organizacional, por sua vez, está relacionada com os resultados favoráveis aos trabalhadores: satisfação no trabalho, humor positivo, e à organização: comprometimento afetivo, melhor desempenho e diminuição do comportamento de absenteísmo. Ao examinarem o quadro de investigação teórica sobre percepção de suporte organizacional, os autores identificaram as seguintes variáveis:

- antecedentes de percepção de suporte organizacional: procedimentos organizacionais adequados, suporte da supervisão, recompensas favoráveis e condições de trabalho.

- consequências de percepção de suporte organizacional: comprometimento afetivo com a organização, crescimento de desempenho e redução de intenção de sair da organização.

A percepção de suporte que o trabalhador percebe na organização impacta diretamente na vida do trabalhador. Siqueira e Gomide Jr. (2004) apresentaram a definição de percepção de suporte organizacional pela relação de troca entre doador e receptor, segundo um esquema mental de reciprocidade em que o doador seria a organização, e o receptor, o empregado.

Coyle-Shapiro e Conway (2005) desenvolveram um estudo longitudinal com 347 funcionários do setor público para investigar quatro ocasiões de medição e distinção conceitual entre o contrato psicológico (obrigações e incentivos percebidos pelo trabalhador) e a percepção de suporte organizacional, e como eles estão associados ao longo do tempo. Os resultados apontaram que os dois conceitos são distintos. Os autores encontraram pouco apoio para uma relação recíproca entre a percepção de suporte organizacional e o cumprimento do contrato psicológico por parte dos trabalhadores. Neste trabalho, os incentivos percebidos pelos trabalhadores foram correlacionados positivamente com a percepção de suporte organizacional, que, por sua vez, foi negativamente relacionada às obrigações da organização percebidas pelo trabalhador. Os resultados sugerem que a percepção de suporte organizacional e os componentes de cumprimento contrato psicológico são mais importantes na previsão do comportamento de cidadania organizacional do que o cumprimento do contrato psicológico.

Siqueira (2005) desenvolveu um estudo que teve como objetivo ampliar a compreensão psicossocial de três conceitos: percepção de suporte, percepção de reciprocidade e comprometimento normativo. Foram apresentadas hipóteses sobre sua integração a um 


\section{Cintia Monteiro Fernandes, Mirlene Maria Matias Siqueira e \\ Almir Martins Vieira}

esquema mental de reciprocidade e sua influência sobre dois critérios afetivos: satisfação no trabalho e comprometimento organizacional afetivo.

Participaram do estudo 483 empregados de empresas particulares e públicas da Grande São Paulo. Os resultados do estudo atestaram a pertinência de se considerar os três conceitos analisados como integrantes do esquema mental de reciprocidade, bem como evidenciaram a capacidade deste esquema para explicar proporções significativas da variância de dois critérios afetivos. A percepção de suporte organizacional revelou-se o componente cognitivo com maior poder de influência sobre satisfação no trabalho e comprometimento afetivo.

Hochwarter e outros (2006) buscaram examinar o efeito moderador da percepção de suporte organizacional sobre a relação entre habilidades sociais e desempenho no trabalho. Foram coletados dados de duas amostras sendo 64 participantes do sexo masculino e 72 do sexo feminino, todos representantes de vendas no sul dos Estados Unidos. Os resultados obtidos sugerem que a habilidade social apresenta efeito sobre o desempenho e pode estar relacionada ao nível de percepção de suporte organizacional.

Shanock e Eisenberger (2006) entrevistaram 180 funcionários de empresas do varejo e 81 supervisores para investigar as relações entre supervisores e subordinados. No estudo com os supervisores, foi investigada a percepção de suporte organizacional que estes possuem da organização. Com os subordinados, foi pesquisada a percepção de suporte do supervisor, com ambos, supervisores e subordinados, relacionados ao desempenho extra. Os autores constataram que a percepção de suporte organizacional dos supervisores foi positivamente relacionada à dos seus subordinados no que se refere a percepções de suporte do supervisor com os empregados. Os resultados desse trabalho sugerem que os supervisores que se sentem apoiados pela organização conseguem estabelecer uma relação de apoio com os subordinados.

Dawley, Houghton e Bucklew (2010) examinaram o papel mediador do ajuste de trabalho sobre a relação entre suporte percebido pelo supervisor e percepção de suporte organizacional e o papel de mediador do sacrifício pessoal sobre a relação entre a variável percepção de suporte organizacional e intenção de rotatividade. Foi usado o modelo de equações estruturais com um conjunto de dados composto por uma amostra de 346 indivíduos em uma empresa de manufatura, para testar o modelo com três variáveis (percepção pelo supervisor, percepção de suporte organizacional e intenção de rotatividade). 0 modelo confirmou a hipótese de que a percepção de suporte do supervisor é um preditor da variável percepção de suporte organizacional e que a percepção de suporte organizacional é um preditor da intenção de rotatividade.

Em estudo anterior, Siqueira (2003) comprovou que a percepção de suporte organizacional constitui um forte antecedente de comprometimento afetivo. Essa proposição ressalta que o vínculo afetivo com a organização tende a se tornar mais fortalecido à medida que os empregados percebem a empresa comprometida com eles. Dada tal relação, é mister tratar do comprometimento afetivo enquanto composto teórico neste estudo.

\section{Comprometimento Organizacional}

Mowday et al. (1982) apresentam o conceito de comprometimento organizacional ancorado em três fatores: forte crença e aceitação dos objetivos e valores organizacionais; disposição em exercer um esforço considerável em benefício da organização; e forte desejo de se manter como funcionário da organização. Derivam deste conceito, três enfoques para o estudo do comprometimento organizacional: afetivo, instrumental/calculativo e normativo. Meyer e Allen (1991) assumem os três enfoques como o consenso das definições de comprometimento organizacional, entendido como um estado psicológico que caracteriza a relação do indivíduo 
para com a organização.

Para este estudo, assumiu-se a dimensão do comprometimento organizacional afetivo, por ser a mais consolidada no universo acadêmico, segundo o que aponta a pesquisa liderada por Lyman Porter (MOWDAY; STEERS; PORTER, 1979; MOWDAY; PORTER; STEERS, 1982). A dimensão do comprometimento instrumental/calculativo decorre dos estudos de Becker (1960), que apresentou o comprometimento instrumental como uma tendência do indivíduo em se engajar em linhas consistentes de atividade. Quanto ao componente normativo do comprometimento organizacional, de acordo com McGee e Ford (1987), trata-se do comprometimento baseado no sacrifício pessoal, associado à possibilidade de deixar a organização.

\section{Comprometimento Organizacional Afetivo}

De acordo com Mowday, Steers e Porter (1979), o comprometimento organizacional afetivo é um estado em que o empregado se identifica com a organização, desejando nela permanecer para alcançar seus objetivos. Os autores desenvolveram o primeiro instrumento de medida de comprometimento organizacional, chamado Organizational Commitment Questionnaire (OCQ), com uma escala de quinze itens com propriedades psicométricas aceitáveis. Esse instrumento foi traduzido, adaptado e validado para a realidade brasileira por Borges-Andrade, Afanasief e Silva (1989), encontrando um coeficiente alpha de 0,86. Anos mais tarde, Allen e Meyer (1990) criaram e validaram o instrumento com vinte e quatro itens, contendo três fatores (comprometimento afetivo, calculativo e normativo) com oito itens para cada fator, tendo índices de precisão de 0,87, 0,75 e 0,79, respectivamente. Após esse período, Siqueira (1995) desenvolveu a construção e a validação da Escala de Comprometimento Organizacional Afetivo (ECOA), definindo a ligação afetiva com a organização como experiências que trazem sentimentos positivos (entusiasmo, alegria, apego, dentre outros).

Sousa e Mendonça (2009) tiveram como objetivo analisar o poder mediacional do comprometimento organizacional afetivo na relação entre as percepções de justiça distributiva, processual e interacional e o burnout. Participaram da pesquisa 233 professores universitários. 0 poder mediacional do comprometimento organizacional afetivo se confirmou na relação entre percepção de justiça distributiva e exaustão. 0 estudo concluiu que a percepção de injustiça na forma de distribuição de recursos pode levar o professor universitário à exaustão, o que pode ter probabilidade aumentada diante da falta de comprometimento organizacional afetivo.

Rousseau e Aubé (2010) apontaram em seu estudo que o suporte do supervisor e o suporte de colega de trabalho podem estar positivamente relacionados com o comprometimento organizacional afetivo do empregado. A amostra incluiu 215 participantes de uma organização de saúde. Os resultados da análise de regressão mostraram que o suporte do supervisor e suporte de colega de trabalho têm um efeito aditivo sobre o comprometimento organizacional afetivo, principalmente quando a adequação de recursos de trabalho é favorável.

Uma que vez esta pesquisa teve por objetivo analisar a relação entre estilos de liderança, percepção de suporte organizacional e comprometimento organizacional afetivo em trabalhadores, foi necessário elaborar um modelo conceitual e um conjunto de hipóteses para, caso seja comprovada a veracidade de cada uma, oferecer sustentação empírica para o modelo (figura 1). 


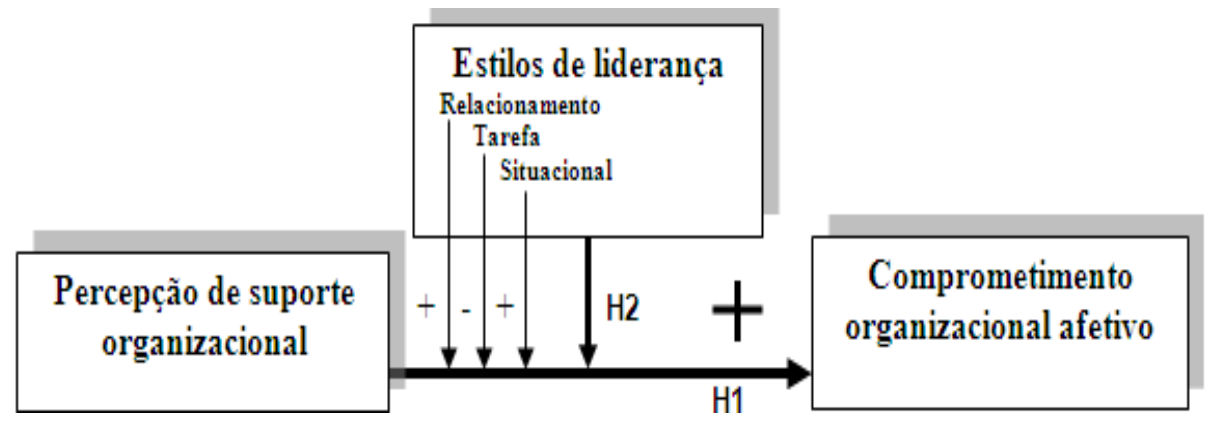

Figura 1. Modelo do papel moderador de estilos de liderança sobre a relação entre percepção de suporte organizacional e comprometimento organizacional afetivo

Fonte: elaborado pelos autores

\section{Hipóteses}

H1: Existe impacto positivo e significativo de percepção de suporte organizacional sobre comprometimento organizacional afetivo

H2: Existe efeito moderador significativo de estilos de liderança na relação entre percepção de suporte organizacional e comprometimento organizacional afetivo.

H2a: Estilo de liderança “relacionamento' pode aumentar o impacto de percepção de suporte organizacional sobre comprometimento organizacional afetivo

H2b: Estilo de liderança 'tarefa' pode reduzir o impacto de percepção de suporte organizacional sobre comprometimento organizacional afetivo

H2c: Estilo liderança 'situacional' pode aumentar o impacto de percepção de suporte organizacional sobre comprometimento organizacional afetivo

\section{Procedimentos Metodológicos}

Este estudo, de caráter quantitativo, toma por base uma proposta baseada nas tipologias descritiva e explicativa (RAUPP; BEUREN, 2003), de modo a permitir que o pesquisador desenvolva e esclareça conceitos e ideias, validando ou reformulando as hipóteses, além de aumentar sua experiência sobre o tema (SIQUEIRA; VIEIRA, 2012).

O número de participantes foi definido a partir do critério estabelecido de Tabachnick e Fidell (2001) para testar preditores por meio da análise de regressão múltipla. Este critério aponta alguns procedimentos para ajudar a decidir quantos casos são necessários para compor a amostra, devendo o cálculo ser realizado considerando-se o número de variáveis independentes ou preditoras, por meio da fórmula: $\mathrm{n} \geq 50+8 \times$ (números de variáveis independentes) $=$ quantidade mínima de participantes para a amostra.

Os modelos de regressão analisados estão constituídos por cinco variáveis independentes: duas variáveis controle, não incluídas no modelo teórico mas, por indicação de Cohen e Cohen (1983), são necessárias para modelos de regressão em que se busca analisar efeitos moderadores; percepção de suporte organizacional, que se constitui como variável preditora; um estilo de liderança (relacionamento, tarefa ou situacional) e uma variável obtida da interação entre a variável critério e uma das dimensões de estilos de liderança. Assim, este estudo poderia contar com a quantidade mínima de 90 participantes. Tal número representa a multiplicação do número de observações, considerando a fórmula: n $\geq 50$ + 08 x 05 = 90 . 
Participaram do estudo, respondendo ao questionário, 265 trabalhadores.

No entanto, quando foram excluídos os questionários que apresentavam outliers e respostas omissas, restaram 263 respondentes. A idade variou entre 18 e 64 anos, com idade média de $34,40$ anos ( $D P=8,88)$, estando a maior concentração $(23,2 \%)$ na faixa de idade entre 26 a 30 anos. 0 grupo foi constituído, em sua maioria, por mulheres $(55,5 \%)$ e o tempo de serviço desses trabalhadores apresentou média de 1,94 anos (DP $=0,67$ ). 0 estado civil predominante apontado foi o casado, com 60,84\%. 0 tempo de trabalho entre dois e dez anos representou $55,1 \%$ dos participantes, os quais, em sua maioria, não ocupam cargo de liderança $(56,70 \%)$. Foram coletados dados de participantes que trabalham em organizações privadas $(71,1 \%)$, organizações públicas $(26,2 \%)$ e organizações não governamentais (2,7\%), localizadas em 19 cidades dos estados de São Paulo e Rio de Janeiro.

A coleta de dados foi realizada por meio de instrumento criado no ambiente Surveymonkey. Esse sistema permitiu a criação de um questionário eletrônico, sendo que os respondentes tiveram acesso ao questionário via e-mail, composto pelas seguintes escalas para avaliação das variáveis de pesquisa:

\section{Escala de Avaliação do Estilo Gerencial}

Permitiu ao trabalhador descrever 19 componentes de sua chefia por meio de uma escala de 5 pontos (1=nunca age assim, 2=raramente age assim, 3=ocasionalmente age assim, 4=frequentemente age assim e 5=sempre agem assim), construída e validada por Melo (2004), tendo como índice de precisão um valor de 0,94 para o fator relacionamento (exemplo: encontra tempo para ouvir os membros do grupo); 0,72 para o fator tarefa (exemplo: valoriza a disciplina e a subordinação); e 0,83 para o fator situacional (exemplo: dá liberdade de trabalho aos subordinados que se mostram seguros diante da tarefa a ser executada). Para compor as dimensões do instrumento, Melo (2004) recorreu a algumas bases teóricas para cada estilo de liderança: Relacionamento - dimensão do comportamento do líder "consideração" (LIKERT, 1971); nos estudos da Michigan University, supervisão concentrada no empregado (LIKERT, 1971); na grade gerencial de Blake e Mouton (1975), preocupação com os empregados; nos estudos de Fiedler (1967), "orientação para o relacionamento"; e nos estudos de Vroom e Yetton (1973), pelos comportamentos denominados "consultores"; Tarefa - estrutura inicial (LIKERT, 1971), nos estudos da Michigan University, supervisão concentrada no serviço (LIKERT, 1971); na grade gerencial de Blake e Mouton (1975), preocupação com a produção/resultados; nos estudos de Fiedler (1967), "orientação para a tarefa"; e nos estudos de Vroom e Yetton (1973) pelos comportamentos do líder denominados "autocráticos"; Situacional - teorias contingenciais propostas por Hersey e Blanchard (1986), para quem o estilo de liderança apropriado depende do nível de maturidade do empregado.

\section{Escala de Percepção Suporte Organizacional}

Foi originalmente construída e validada por Eisenberger e outros (1986) e validada para o Brasil por Siqueira (1995), constituindo-se em uma escala que, em sua forma, é composta por seis frases, tendo como índice de precisão um valor de 0,86 . As respostas foram dadas em uma escala de sete pontos (1=discordo totalmente, 2=discordo moderadamente, $3=$ discordo levemente, $4=$ nem concordo, nem discordo, $5=$ concordo levemente, $6=$ concordo moderadamente e $7=$ concordo totalmente).

\section{Escala de Comprometimento Organizacional Afetivo}


É uma medida unidimensional que permite avaliar a intensidade com que um empregado nutre sentimentos positivos e negativos frente à organização que o emprega.

A escala foi construída e validada por Siqueira (1995), composta por 18 itens, apresentando valores de correlação entre 0,50 e 0,83. 0 índice de precisão da escala foi de 0,95 (Tabela 11). A autora selecionou os itens com maior correlação item-total e criou uma versão reduzida com cinco itens, com confiabilidade igual a 0,93 (exemplo: orgulhoso (a) dela), já considerado satisfatório para investigação científica. As respostas foram dadas em uma escala de cinco pontos ( 1 =nada, $2=$ pouco, $3=$ mais ou menos, $4=$ muito e $5=$ extremamente $)$.

\section{Análise dos dados}

Foi realizada, a priori, uma análise exploratória dos dados para verificar a precisão de entrada de dados, outliers e respostas omissas. As análises incluíram a aplicação de estatísticas descritivas, com apresentação de médias, desvios-padrão, frequências, percentuais, valores para alfas de Cronbach, teste $t$ de Student, coeficientes de correlação ( $r$ de Pearson) entre as seguintes variáveis: estilos de liderança, percepção de suporte organizacional e comprometimento organizacional afetivo. Antes de se iniciar as análises de regressão, alguns itens propostos por Pallant (2007) foram checados. Após a exploração dos dados, análises estatísticas multivariadas foram realizadas por meio de regressão linear múltipla hierárquica moderadora, pelo método (enter) padrão, utilizando-se o subprograma regression do SPSS(versão 18.0) para aferir a capacidade moderadora de estilos de liderança na relação entre percepção de suporte organizacional e comprometimento organizacional afetivo.

\section{Resultados e Discussão}

Os resultados foram organizados em duas seções. Na primeira seção são apresentados, interpretados e discutidos os resultados das análises descritivas referentes às médias e desviospadrão, índices de precisão, valores do teste $t$ e correlações das variáveis estilos de liderança, percepção de suporte organizacional e comprometimento organizacional afetivo. Na seção seguinte, os mesmos procedimentos são realizados em relação aos resultados de modelo de regressão linear múltipla hierárquica moderadora, pelo método-padrão (enter), a fim de demonstrar a contribuição de cada variável independente na explicação da variável dependente.

\section{Análises descritivas}

Realizou-se uma análise preliminar, com o intuito de verificar a precisão da entrada dos dados, respostas omissas, casos extremos, normalidade das variáveis. A Tabela 1 apresenta os índices de confiabilidade das escalas utilizadas no estudo. Estas análises foram obtidas por meio do comando “Descriptives" do programa SPSS versão 18.0.

\begin{tabular}{llllll}
\hline Variáveis & Médias & DP & $\begin{array}{l}\text { Valores } \\
\text { das escalas }\end{array}$ & $\begin{array}{l}\text { Índices de } \\
\text { precisão }\end{array}$ & Valores de $t$ \\
\hline Estilos de liderança 'relacionamento' & 3,66 & 0,84 & 1 a 5 & 0,93 & $12,780^{* *}$ \\
\hline
\end{tabular}




\section{IMPACTO DA PERCEPÇÃO DE SUPORTE ORGANIZACIONAL SOBRE O COMPROMETIMENTO ORGANIZACIONAL AFETIVO: O PAPEL MODERADOR DA LIDERANÇA}

\begin{tabular}{|c|c|c|c|c|c|}
\hline Estilos de liderança 'tarefa' & 4,05 & 0,62 & 1 a 5 & 0,73 & $27,658^{* *}$ \\
\hline Estilos de liderança 'situacional' & 3,87 & 0,80 & 1 a 5 & 0,85 & $17,702^{* *}$ \\
\hline Percepção de suporte organizacional & 4,72 & 1,12 & 1 a 7 & 0,86 & $8,218^{* *}$ \\
\hline $\begin{array}{l}\text { Comprometimento } \\
\text { afetivo }\end{array}$ & 3,38 & 0,97 & 1 a 5 & 0,95 & $6,373^{* *}$ \\
\hline
\end{tabular}

Tabela 1: Variáveis do estudo e índices de confiabilidade das escalas ( $n=263$ )

Fonte: elaborado pelos autores

A média dimensão de estilos de liderança "relacionamento" (média=3,66; DP=0,84; $t=12,780$; $\mathrm{p}<0,01$ ), ficou significativamente acima do ponto médio da escala de respostas (valor=3). Esta dimensão de liderança reúne itens que se referem ao comportamento da chefia que, segundo os empregados, a chefia "ocasionalmente age assim" em termos de disponibilidade para dar atenção e ouvi-los, respeitar as suas ideias, compreender as suas falhas, além de se interessar pelos seus sentimentos. Tais resultados assemelham-se aos estudos de Meleiro (2005) e de Isidro-Filho (2006). A média dimensão de estilos de liderança "tarefa" (média=4,05; DP=0,62; $t=27,658 ; \mathrm{p}<0,01)$ ficou significativamente acima do ponto médio da escala de respostas (valor=3). Esta dimensão de liderança reúne itens que se referem ao comportamento da chefia nos termos de valorização da hierarquia, rigidez no cumprimento de prazo, prioridade na execução de tarefas e de seguir normas e regras estabelecidas. Segundo os participantes deste estudo, suas chefias "frequentemente agem assim". Tais resultados obtidos aproximam-se do que apontou o trabalho de Meleiro (2005). A média dimensão de estilo de liderança "situacional" (média $=4,05 ; \mathrm{DP}=0,62 ; \mathrm{t}=17.702 ; \mathrm{p}<0,01$ ), ficou significativamente acima do ponto médio da escala de respostas (valor=3). Esta dimensão de liderança reúne comportamentos flexíveis das chefias em que o estilo de liderança apropriado está de acordo com o nível de maturidade do empregado (MELEIRO, 2005; ISIDRO-FILHO, 2006).

\section{Análises de regressão múltipla}

A regressão múltipla é definida por Tabachnick e Fidell (2001) como um conjunto de técnicas estatísticas para avaliação do relacionamento de uma variável dependente com diversas variáveis independentes. Ao optar pela regressão múltipla, alguns pressupostos foram observados, conforme critério estabelecido por Pallant (2007), para assegurar a não-violação dos pressupostos de normalidade, linearidade, multicolinearidade e homostecidade. Foi necessária a retirada de um caso (participante 100) para o estilo de liderança relacionamento e situacional e a retirada de dois casos (participantes 57 e 100) para o estilo de liderança tarefa, porque o valor de Mahalanobis Distance excedia a 20,52, valor crítico apontado por Pallant (2007) quando o número de variáveis independentes é igual a 5, como ocorreu neste estudo. Na regressão linear múltipla hierárquica, também referida como regressão sequencial, a entrada em blocos das variáveis é definida com base em pressupostos teóricos (PALLANT, 2007).

Quando se trata de investigar o papel moderador de uma variável por meio de regressão hierárquica, Cohen e Cohen (1983) recomendam a introdução de termos interativos, valores produzidos pela multiplicação da variável independente pela variável moderadora.

Tais valores entram no quarto passo da regressão hierárquica. Os autores ainda recomendam a introdução no primeiro bloco de algumas variáveis "controle" que representem algum fator capaz de deter algum valor de explicação da variável dependente, mas que não são considerados como preditoras no modelo colocado sob análise. A análise de regressão linear múltipla 
hierárquica moderadora (ARLMHM) foi usada para verificar a capacidade preditiva de percepção de suporte organizacional sobre comprometimento organizacional afetivo, bem como o papel moderador de três estilos de liderança sobre este relacionamento, com vistas a testar as hipóteses formuladas para este estudo. No caso em questão, formaram o primeiro bloco duas variáveis controle (idade e tempo de serviço na empresa); o segundo bloco foi composto pela variável independente percepção de suporte organizacional; no terceiro bloco, foi inserido, em cada modelo, um dos três estilos de liderança com função moderadora e, no quarto bloco, uma interação entre percepção de suporte organizacional e cada estilo de liderança.

0 primeiro modelo, calculado com as variáveis 'idade' e 'tempo de serviço na empresa', conseguiu explicar 2,80\% (F=3,699; $\left.\mathrm{p}<0,05 ; \Delta \mathrm{R}^{2}=0,028 ; \mathrm{p}<0,05\right)$ da variância de comprometimento afetivo. Como assinala Price (2001), variáveis demográficas sempre refletem a influência de vários fatores e, portanto, não necessitam receber explicações específicas em um modelo de regressão, especialmente quando o modelo teórico sobre investigação não atribui a elas nenhum poder explicativo (figura 2). 0 segundo modelo, com a introdução da variável percepção de suporte organizacional no segundo bloco, acrescentou 44,50\% (F=77,137; $\mathrm{p}<0,01$; $\left.\Delta \mathrm{R}^{2}=0,445 ; \mathrm{p}<0,01\right)$ de explicação, enquanto a variável moderadora estilo de liderança 'relacionamento', posicionada no terceiro bloco, conseguiu acrescer ao percentual de explicação $1,30 \%\left(\mathrm{~F}=60,682 ; \mathrm{p}<0,01 ; \Delta \mathrm{R}^{2}=0,013 ; \mathrm{p}<0,05\right)$. No quarto bloco, quando se acrescentou ao modelo a interação entre percepção de suporte organizacional e estilo de liderança 'relacionamento', houve um aumento de 0,05\% ( $\mathrm{F}=49,420 ; \mathrm{p}<0,01 ; \Delta \mathrm{R}^{2}=0,005$; NS) não significativo.

\begin{tabular}{|c|c|c|c|c|}
\hline \multirow[b]{2}{*}{ Variáveis } & \multicolumn{4}{|c|}{ Comprometimento organizacional afetivo } \\
\hline & $\begin{array}{l}\text { Modelo } 1 \\
\beta\end{array}$ & $\begin{array}{l}\text { Modelo } 2 \\
\beta\end{array}$ & $\begin{array}{l}\text { Modelo } 3 \\
\beta\end{array}$ & $\begin{array}{l}\text { Modelo } 4 \\
\beta\end{array}$ \\
\hline \multicolumn{5}{|l|}{ Bloco 1: variáveis de controle } \\
\hline Idade & 0,009 & $-0,117^{*}$ & $-0,125^{*}$ & $-0,129 *$ \\
\hline Tempo de serviço na empresa & $0,161^{*}$ & $0,161^{* *}$ & $0,165^{* *}$ & $0,159^{* *}$ \\
\hline \multicolumn{5}{|l|}{ Bloco 2: variável independente } \\
\hline Percepção de suporte organizacional & & $0,679^{* *}$ & $0,610^{* *}$ & 0,287 \\
\hline \multicolumn{5}{|l|}{ Bloco 3: variáveis moderadoras } \\
\hline Estilo de liderança 'relacionamento' & & & $0,134^{*}$ & $-0,135$ \\
\hline \multicolumn{5}{|l|}{ Bloco 4: Termos interativos } \\
\hline PSO* Estilo de liderança 'relacionamento' & & & & 0,524 \\
\hline F modelo & $3,699 *$ & $77,137^{* *}$ & $60,682^{* *}$ & $49,420^{* *}$ \\
\hline $\mathbf{R}^{2}$ Modelo & 0,028 & 0,473 & 0,486 & 0,491 \\
\hline$\Delta \mathbf{R}^{2}$ Modelo & $0,028^{*}$ & $0,445^{* *}$ & $0,013^{*}$ & 0,005 \\
\hline \% acrescido à variância explicada pelo modelo & 2,80 & 44,50 & 1,30 & 0,05 \\
\hline
\end{tabular}

Tabela 2: Modelos de regressão linear múltipla hierárquica moderadora para comprometimento organizacional afetivo, variável independente percepção de suporte organizacional e moderadora estilo de liderança 'relacionamento' ( $\mathrm{n}=262)$.

Fonte: elaborado pelos autores

Os resultados da ARLMHM, sobre comprometimento organizacional afetivo (tabela 2), trazem suporte empírico para a H1 (existe impacto positivo e significativo de percepção de suporte organizacional sobre comprometimento organizacional afetivo), mas não revelam valores 
para aceitar como verdadeira a H2a (Estilo de liderança "relacionamento' pode aumentar o impacto de percepção de suporte organizacional sobre comprometimento organizacional afetivo), visto que o quarto modelo de interação entre variável independente e moderadora não produziu um incremento $\left(\Delta \mathrm{R}^{2}\right)$ significativo. Portanto, parece que o estilo de liderança centrado no relacionamento com os subordinados não consegue alterar a força nem a direção do impacto exercido por percepção de suporte organizacional sobre comprometimento organizacional afetivo. Diante de tais evidências, é possível afirmar que as crenças acerca do apoio ofertado pela organização exercem um papel importante na configuração de compromisso afetivo, tendo um poder explicativo elevado sobre sua variação, conforme os valores de beta $(\boldsymbol{\beta})$ apresentados. Por outro lado, comportamentos de líderes com ênfase no relacionamento com seus subordinados não conseguem aumentar nem diminuir de forma significativa o impacto exercido pelo conjunto de crenças do empregado acerca de o quanto o seu empregador se preocupa com ele.

Na sequência, são apresentadas as tabelas 3 e 4. Elas contêm as mesmas variáveis introduzidas na tabela 2. Portanto, os resultados dos modelos 1 e 2 das tabelas 3 e 4 são idênticos aos da tabela 2 no tocante à ARLMHM para comprometimento organizacional afetivo, isso porque o primeiro bloco trata das mesmas duas variáveis controle e o segundo bloco trata da variável independente que não muda nas três tabelas. A partir do terceiro bloco ocorre uma mudança, pois é inserida a função moderadora para cada estilo de liderança, e o quarto bloco trata da interação entre percepção de suporte organizacional e cada estilo de liderança. Durante as análises preliminares, foi detectado um caso comprometedor dos pressupostos de regressão e o mesmo foi eliminado (caso 57) ficando o número de participantes reduzido a 261.

0 terceiro bloco apresentado (Tabela 3) conseguiu acrescer ao percentual de explicação 0,02\% $\left(\mathrm{F}=60,503 ; \mathrm{p}<0,01 ; \Delta \mathrm{R}^{2}=0,002 ; \mathrm{p}<0,05\right)$, significativo para a variável moderadora estilo de liderança 'tarefa'. No quarto bloco, quando se acrescentou ao modelo a interação entre percepção de suporte organizacional e estilo de liderança 'tarefa' houve um aumento de 0,01\% $\left(\mathrm{F}=48,435 ; \mathrm{p}<0,01 ; \Delta \mathrm{R}^{2}=0,001 ; \mathrm{NS}\right)$ não significativo. Diante desse panorama, $\mathbf{H} 2 \mathbf{b}$ foi rejeitada, visto que não existem evidências da capacidade do estilo de liderança 'tarefa' alterar significativamente a direção do impacto exercido por percepção de suporte organizacional sobre comprometimento organizacional afetivo.

\begin{tabular}{l|l|l|l|l}
\hline \multirow{2}{*}{ Variáveis } & \multicolumn{3}{|l}{ Comprometimento organizacional afetivo } \\
\cline { 2 - 5 } & Modelo 1 & Modelo 2 & Modelo 3 & Modelo 4 \\
& $\beta$ & $\beta$ & $\beta$ & $\beta$ \\
\hline
\end{tabular}

Bloco 1: variáveis de controle 
Idade

Tempo de serviço na empresa

Bloco 2: variável independente

Percepção de suporte organizacional

Bloco 3: variáveis moderadoras

Estilo de liderança 'tarefa'

Bloco 4: Termos interativos

PSO* Estilo de liderança 'tarefa'

F modelo

$\mathbf{R}^{2}$ Modelo

$\Delta \mathbf{R}^{2}$ Modelo

\% acrescido à variância explicada pelo modelo
0,009
$-0,117^{*}$
$-0,125^{*}$
$-0,129 *$
$0,161^{*}$
$0,161^{* *}$
$0,165^{* *}$
$0,159 * *$

$0,679 * * \quad 0,610^{* *}$

$0,048^{*}$

$-0,087$

0,300

3,599*

80,290 **

$60,503^{* *}$

$48,435^{* *}$

0,027

0,484

0,486

0,487

$0,027^{*}$

$0,457^{* *}$

$0,002 *$

0,001

2,70

45,70

0,02

0,01

Tabela 3: Modelos de regressão linear múltipla hierárquica moderadora para comprometimento organizacional afetivo, variável independente percepção de suporte organizacional e moderadora estilo de liderança 'tarefa' (n= 261).

Fonte: elaborado pelos autores

Por fim, são apresentados os resultados a partir do terceiro bloco da tabela 4 , no qual se conseguiu acrescer ao percentual de explicação $0,08 \%\left(F=59,624 ; p<0,01 ; \Delta R^{2}=0,008 ; p<0,05\right)$, significativo para a variável moderadora estilo de liderança 'situacional'. No quarto bloco, quando se acrescentou ao modelo a interação entre percepção de suporte organizacional e estilo de liderança 'situacional' houve um aumento de $0,03 \%\left(\mathrm{~F}=48,115 ; \mathrm{p}<0,01 ; \Delta \mathrm{R}^{2}=0,03 ; \mathrm{NS}\right)$ não significativo. Diante dessas constatações, H2c foi rejeitada, visto que não existem evidências da capacidade do estilo de liderança 'situacional' alterar significativamente a direção do impacto exercido por percepção de suporte organizacional sobre comprometimento organizacional afetivo.

\begin{tabular}{l|l|l|l|l}
\hline \multirow{2}{*}{ Variáveis } & \multicolumn{4}{|l}{ Comprometimento organizacional afetivo } \\
\cline { 2 - 5 } & Modelo 1 & Modelo 2 & Modelo 3 & Modelo 4 \\
& $\beta$ & $\beta$ & $\beta$ & $\beta$ \\
\hline
\end{tabular}

Bloco 1: variáveis de controle 


\section{IMPACTO DA PERCEPÇÃO DE SUPORTE ORGANIZACIONAL SOBRE O COMPROMETIMENTO ORGANIZACIONAL AFETIVO: O PAPEL MODERADOR DA LIDERANÇA}

Idade

Tempo de serviço na empresa

$$
0,009
$$

$0,161^{*}$
$-0,117^{*}$

$0,161^{* *}$

$-0,125^{*}$

$0,165^{* *}$

$-0,129 *$

Bloco 2: variável independente

Percepção de suporte organizacional

Bloco 3: variáveis moderadoras

Estilo de liderança 'situacional'

Bloco 4: Termos interativos

PSO* Estilo de liderança 'situacional'

F modelo

$\mathbf{R}^{2}$ Modelo

$\Delta \mathbf{R}^{2}$ Modelo

\% acrescido à variância explicada pelo modelo

$$
0,679^{* *}
$$$$
0,610^{* *}
$$

$0,107^{*}$

$-0,091$

\begin{tabular}{llll} 
& & & 0,401 \\
$3,699^{*}$ & $77,137^{* *}$ & $59,624^{* *}$ & $48,115^{* *}$ \\
0,028 & 0,473 & 0,481 & 0,484 \\
$0,028^{*}$ & $0,445^{* *}$ & $0,008^{*}$ & 0,003 \\
2,80 & 44,50 & 0,08 & 0,03 \\
\hline & & & ${ }^{*} \mathrm{p}<0,05 ;{ }^{* *} \mathrm{p}<0,01$
\end{tabular}

Tabela 4: Modelos de regressão linear múltipla hierárquica moderadora para comprometimento organizacional afetivo, variável independente percepção de suporte organizacional e moderadora estilo de liderança 'situacional' $(n=261)$.

Fonte: elaborado pelos autores

Os resultados da ARLMHM sobre comprometimento organizacional afetivo contidos na tabela 4 não revelam valores para aceitar como verdadeira a H2 (existe efeito moderador significativo de estilos de liderança na relação entre percepção de suporte organizacional e comprometimento organizacional afetivo). Portanto, o impacto exercido por percepção de suporte organizacional sobre comprometimento organizacional afetivo não sofre interferência significativa do estilo de liderança situacional que seja capaz de alterar positivamente este valor de impacto.

Os resultados de ARLMHM aqui apresentados permitem afirmar a sensibilidade existente no vínculo afetivo que o trabalhador nutre por sua empresa empregadora diante de suas próprias percepções de suporte, como já revelado por estudos anteriores (PADOVAM, 2005; OLIVEIRA, 2006; PEREIRA, 2009; BARBOSA, 2010). Por outro lado, os três estilos de liderança apontados neste estudo como possíveis moderadores dessa relação não obtiveram suporte empírico nas análises efetuadas. Assim, parece que independentemente do estilo de liderança adotado pelos líderes, o vínculo do trabalhador com a organização flutuará consoante suas percepções de que ela (a organização) se comporta de forma a suscitar em seus colaboradores crenças de que há uma política organizacional de gestão de pessoas voltada para zelar pelo bem-estar pessoal e profissional de cada um.

\section{Considerações Finais}

Este trabalho propôs-se a analisar as relações entre as variáveis estilos de liderança, percepção de suporte organizacional e comprometimento organizacional, apresentando, interpretando e discutindo os escores médios, os índices de correlação entre as mesmas, bem como o papel moderador de estilos de liderança na relação de percepção de suporte organizacional e comprometimento organizacional afetivo.

Entre as hipóteses formuladas, foi confirmada a H1 (existe impacto positivo e significativo de percepção de suporte organizacional sobre comprometimento organizacional afetivo) pois, no tocante às correlações, o maior índice encontrado foi entre as variáveis percepção de suporte 
organizacional e comprometimento organizacional afetivo, demonstrando assim que os participantes deste estudo percebem suporte organizacional e, ao mesmo tempo, parecem estar comprometidos afetivamente com a sua organização. Não foi possível atestar como verdadeira a H2 (existe efeito moderador significativo de estilos de liderança na relação entre percepção de suporte organizacional e comprometimento organizacional afetivo), visto que a interação entre variável independente e moderadora "relacionamento" não produziu um incremento $\left(\Delta \mathrm{R}^{2}\right)$ significativo. Portanto, o estilo de liderança centrado no relacionamento com os subordinados não conseguiu alterar a força nem a direção do impacto exercido por percepção de suporte organizacional sobre comprometimento organizacional afetivo. As hipóteses H2b e H2c foram rejeitadas, pois não existem evidências da capacidade dos estilos de liderança 'tarefa' e 'situacional' alterarem significativamente a direção do impacto exercido por percepção de suporte organizacional sobre comprometimento organizacional afetivo. Os três estilos de liderança apontados neste estudo como possíveis moderadores dessa relação, não obtiveram suporte empírico nas análises efetuadas. Diante de tais resultados, pode-se observar que os níveis de percepção de suporte do empregado podem ser fortalecidos ou enfraquecidos de acordo com as políticas de gestão de pessoas adotadas na organização. Ou seja, pelo panorama constatado na pesquisa, é possível inferir que cabe à organização fazer com que o empregado tenha compromisso afetivo. Eis um papel crucial da própria organização enquanto cenário onde atuam grupos de pessoas. As contribuições deste estudo elucidam aspectos voltados à área do comportamento organizacional, uma vez que não foram encontrados na literatura estudos em que o estilo de liderança tenha sido tomado como variável moderadora na relação entre percepção de suporte organizacional e comprometimento organizacional afetivo. Tem-se um fator de troca, pois, por parte do empregado, a percepção de suporte leva ao comprometimento organizacional, sem depender do estilo de liderança.

Cabe-nos indicar as seguintes questões para futuras pesquisas: Já que estilo de liderança não interfere na relação de percepção de suporte organizacional e comprometimento organizacional afetivo, será que se utilizar percepção de suporte organizacional como variável moderadora pode trazer outras indicações? Outro estudo poderia investigar o papel do salário (ou demais benefícios) recebido pelos participantes, adotando as mesmas variáveis para análise por faixa salarial, para então verificar se haverá diferença nos resultados dos grupos envolvidos.

Como sugestões de aplicação prática, considera-se que manter o empregado comprometido demanda que as organizações invistam mais em suportes organizacionais, pois, de acordo com os resultados apontados neste estudo, o empregado que acredita poder contar com a organização empregadora e nela perceber preocupação com seu bem-estar e com sua satisfação, tende a ser mais comprometido.

\section{Referências}

ALLEN, N. J.; MEYER, J. P. The measurement and antecedents of affective, continuance and normative commitment to the organization. Journal of Occupational Health Psychology, v. 63, p.1-18, 1990.

ARONSON, E. Integrating leadership styles and ethical perspectives. Canadian Journal of Administrative Sciences, v.18, n.4, p.244-256, 2001.

BARBOSA, T. S. Os impactos do balanço emocional, otimismo e percepções de suportes sobre bem-estar no trabalho de agentes comunitários de saúde. 109 f. Dissertação (Mestrado em Psicologia da Saúde) - Faculdade de Psicologia e Fonoaudiologia, Universidade Metodista de São Paulo, São Bernardo do Campo, 2010.

BECKER, H. S. Notes on the concept of commitment. The American Journal of Sociology, v. 66, 
p. 3240,1960 .

BERGAMINI, C. W. Liderança: a administração do sentido. Rev. adm. empres. [online], vol.34, n.3, pp. 102-114, 1994.

BISQUERRA, R.; SARRIERA, J. C.; MARTINEZ, F. Introdução à estatística: enfoque informático com o pacote estatístico SPSS. Porto Alegre: Artmed, 2004.

BLAKE, R. R.; MOUTON, J. S. 0 grid gerencial. São Paulo: Pioneira, p. 329, 1975.

BORGES-ANDRADE, J. E.; AFANASIEFF, R. S.; SILVA, M. S. Mensuração de comprometimento organizacional em instituições públicas. Sociedade Brasileira de Psicologia (Org.). XIX Reunião Anual de Psicologia. Resumos... Ribeirão Preto: SBP, p. 236, 1989.

COHEN, J.; COHEN, P. Applied multiple regression correlation analysis for the behavioral sciences. New York: Lawrence Erlbaum Associates, 1983.

COYLE-SHAPIRO, J. A. M.; CONWAY, N. Exchange relationships: examining psychological contracts and perceived organizational support. Journal of Applied Psychology, v. 90, n. 4, p. 774-781, 2005.

DAVISON, R. M.; JIBAO G. , HUANG. Q.; LIU. H. The impact of leadership style on knowledgesharing intentions in china. Journal of Global Information Management. v.16, n.4 p.67, 2008.

DAWLEY, D.; HOUGHTON J. D; BUCKLEW, N.S. Perceived Organizational Support and Turnover Intention: The Mediating Effects of Personal Sacrifice and Job Fit. The Journal of Social Psychology, v.150 n.3, p.238-257, 2010.

EISENBERGER, R.; HUNTINGTON, R.; HUTCHISON, S.; SOWA, D. Perceived organizational support. Journal of Applied Psychology, v. 71, n. 3, p. 500-507, 1986.

EUWEMA M. C; WEND. H; EMMERIK H. V. Leadership styles and group organizational citizenship behavior across culture. Journal of Organizational Behavior, v. 28, p.1035-1057, 2007.

GIRI, V. N.; SANTRA, T. Effects of job experience, career stage, and hierarchy on leadership style. Singapore Management Review. v. 32. N.1, p. 85, 2010.

GOLEMAN, D. Inteligência emocional: a teoria revolucionária que redefine o que é ser inteligente. Rio de Janeiro: Objetiva, 1995.

GOLEMAN, D. O Poder da inteligência emocional: a experiência de liderar com sensibilidade e eficácia. Rio de Janeiro: Campus, 2002.

GOSENDO, E. E. M.; TORRES, C. V. Influência dos valores organizacionais sobre estilos de gerenciamento em empresas de pequeno porte. Paidéia (Ribeirão Preto). vol.20, n.45, pp. 29$38,2010$.

HERSEY, P; BLANCHARD, K. H. Psicologia para administradores: a teoria e as técnicas da liderança situacional. São Paulo: E.P.U., 1986.

HOCHWARTER, W. A.; WITT, L. A.; TREADWAY, D. C.; FERRIS, G. R. The Interaction of Social Skill and Organizational Support on Job Performance. Journal of Applied Psychology. v. 91, n. 2, p. 482-489, 2006.

HOFSTEDE, G. Culture's consequences: Comparing values, behaviors, institutions, and organizations across nations. Thousand Oaks, CA: Sage, 2001.

ISIDRO-FILHO, A. Mecanismos e cultura de aprendizagem em organizações: análise de suas 
relações com liderança em uma organização financeira. 141 f. Dissertação (Mestrado em Administração Gestão Social e Trabalho) - Universidade de Brasília, Brasília, 2006.

JOHNSON N. J; KLEE T. Leadership Style and Team Processes in Self-Managed Teams. Journal of Leadership \& Organizational Studies. v.14. n.2. p130, 2007.

LEWIN, K.; LIPPITT, R.; WHITE, R. Patterns of aggressive behaviors in experimentally created social climates. Journal of Social Psychology, 10, 271- 299, 1939.

LIKERT, R. Novos padrões de administração. São Paulo: Pioneira, 1971.

LINDGREEN, A.; PALMER, R.; WETZELS, M. Do different marketing practices require different leadership styles? an exploratory study. Journal of Business \& Industrial Marketing, v. 24. n.1, p.14, 2009.

MAYER, J. D., DIPAOLO, M.T.; SALOVEY, P. Perceiving affective content in ambiguous visual stimuli: a component of emotional intelligence. Journal of Personality Assessment, v.54, p.772-781, 1990.

McALLISTER, D. Affect- and cognition-based trust as foundations for interpersonal cooperation in organizations. Academy of Management Journal, 38, 24-59, 1995.

McGEE, G. W.; FORD, R. C. Two (or more?) dimensions of organizational commitment: reexamination of the affective and continuance commitment scales. Journal of Applied Psychology, v. 72, n. 4, p. 638-641, 1987.

MELEIRO, A. R. Bem-estar no trabalho: os impactos do suporte do supervisor e de estilos de liderança. 112 f. Dissertação (Mestrado em Psicologia da Saúde) - Faculdade de Psicologia e Fonoaudiologia, Universidade Metodista de São Paulo, São Bernardo do Campo, 2005.

MELO, E. A. A. Comprometimento organizacional, estilos gerenciais e poder organizacional: um estudo relacional. 120 f. Dissertação (Mestrado em Psicologia) Universidade de Brasília, Brasília, 2001.

MELO, E. A. A. Escala de Avaliação do Estilo Gerencial (EAEG): desenvolvimento e validação. Revista Psicologia: Organizações e Trabalho RPOT, vol. 4 n.2, p.31-32, 2004.

MEYER, J. P.; ALLEN, N. J. A three-component conceptualization of organizational commitment. Human Resource Management Review, v. 1, p. 61-89, 1991.

MOWDAY, R. T.; STEERS, R. M.; PORTER, L. W. The measurement of organizational commitment. Journal of Vocational Behavior, v. 14, p.224-247, 1979.

MOWDAY, R. T.; PORTER, L. W.; STEERS, R. M. Employee-organization linkages: the psychology of commitment, absenteism and turnover. New York: Academic Press, 1982.

OLIVEIRA, B. Comprometimento organizacional: os impactos das percepções de cultura e suportes organizacionais. 132 f. Dissertação (Mestrado em Psicologia) - Instituto de Psicologia, Universidade Federal de Uberlândia, 2006.

OLIVEIRA, A.; TAMAYO, A. Inventário de perfis de valores organizacionais. Revista de Administração da Universidade de São Paulo, v. 369, n. 2, p. 129-140, abr./jun. 2004.

PADOVAM, V. A. R. Antecedentes de bem-estar no trabalho: percepções de suportes e de justiça. 119 f. Dissertação (Mestrado em Psicologia da Saúde) - Faculdade de Psicologia e Fonoaudiologia, Universidade Metodista de São Paulo, São Bernardo do Campo, 2005.

PALLANT, J. SPSS Survival Manual. Open University Press, 2007. 
PANTOJA, S. G. Liderança: uma relação eficaz. 162 f. Dissertação (Mestrado em Engenharia Mecânica) - Faculdade de Engenharia Mecânica, Universidade Estadual de Campinas, 2005.

PEREIRA, U. S. B. Relações de suporte e bem-estar no trabalho em pessoas com deficiência. 81 f. Dissertação (Mestrado em Psicologia da Saúde) - Faculdade de Psicologia e Fonoaudiologia, Universidade Metodista de São Paulo, São Bernardo do Campo, 2009.

PRICE L. Reflections on the Determinant of Voluntary Turnover. International Journal of Manpower, v. 12, 115-141, 2001.

RAUPP, F. M.; BEUREN, I. M. Metodologia da pesquisa aplicável às ciências sociais. In: LONGARAY, A. A.; BEUREN, I. M. (org.). Como elaborar trabalhos monográficos em contabilidade: teoria e prática. São Paulo: Atlas, 2003.

RHOADES, L; EISENBERGER, R. Perceived Organizational Support: A Review of the Literature. Journal of Applied Psychology, v. 87. nํ 4, 698-714, 2002.

ROBBINS, S. P. Comportamento Organizacional. Editora LTC. 8ª Edição, 1999.

ROUSSEAU, V.; AUBÉ, C. Social Support at Work and Affective Commitment to the Organization: The Moderating Effect of Job Resource Adequacy and Ambient Conditions. Journal of Social Psychology, v.150, n.4, p. 321-340, 2010.

SHANOCK, L. R.; EISENBERGER, R. When supervisors feel supported: relationships with subordinates perceived supervisor support, perceived organizational support, and performance. Journal of Applied Psychology, v. 91, n. 3, p. 689-695, 2006.

SIQUEIRA, D. M.; VIEIRA, A. M. Valores organizacionais: percepção e legitimação. Revista Gestão \& Tecnologia, v. 12, n. 2, p. 168-191, 2012.

SIQUEIRA, M. M. M. Antecedentes de comportamentos de cidadania organizacional: análise de um modelo pós-cognitivo. 265 f. Tese (Doutorado em Psicologia) - Instituto de Psicologia, Universidade de Brasília, Brasília, 1995.

SIQUEIRA, M. M. M. Proposição e análise de um modelo para comportamentos de cidadania organizacional. Revista de Administração Contemporânea, Curitiba, v. 7, n. especial, pp. 165-184, 2003.

SIQUEIRA, M. M. M. Esquema mental de reciprocidade e influências sobre afetividade no trabalho. Estudos de Psicologia. v.10, n1, p.83-93, 2005.

SIQUEIRA, M. M. M. \& GOMIDE JR., S. Vínculos do indivíduo com o trabalho e com a organização. Em J. C. Zanelli, J. E. Borges- Andrade \& A. V. B. Bastos (Orgs), Psicologia, organizações e trabalho no Brasil. Porto Alegre: Artmed, 2004.

SOMECH, A. Women as participative leaders: Understanding participative leadership from a cross-cultural perspective. In OPLATKA, I,; R. HERTZ-LAZAROWITZ, R. (Eds.). Women principals in a multicultural society (pp. 155-74). Rotterdam: Sense Publishers, 2006.

SOUSA, I. F.; MENDONCA, H. Burnout em professores universitários: impacto de percepções de justiça e comprometimento afetivo. Psic.: Teor. e Pesq., Brasília, v. 25, n. 4, dez. 2009.

SOUZA, C. L. C.; TOMEI. P. A. Impactos de uma liderança transacional em um processo de mudança transformacional. Revista Psicologia: Organizações e Trabalho - RPOT, vol. 8 n.2, p. 98-120, 2008. 
TABACHNICK, B.; FIDELL, L. S. Using multivariate statistics. 3 ed. New York: Harper Collins, 2001. 